\title{
Reliability Estimation of Solder Joints Under Thermal Fatigue with Varying Parameters by using FORM and MCS
}

\author{
Ouk Sub Lee, Yeon Chang Park, and Dong Hyeok Kim
}

\begin{abstract}
One of major reasons of failure of solder joints is known as the thermal fatigue. Also, The failure of the solder joints under the thermal fatigue loading is influenced by varying boundary conditions such as the material of solder joint, the materials of substrates(related the difference in CTE), the height of solder, the Distance of the solder joint from the Neutral Point (DNP), the temperature variation and the dwell time. In this paper, first, the experimental results obtained from thermal fatigue test are compared to the outcomes from theoretical thermal fatigue life equations. Second, the effects of varying boundary conditions on the failure probability of the solder joint are studied by using the probabilistic methods such as the First Order Reliability Method (FORM) and Monte Carlo Simulation (MCS).
\end{abstract}

Index Terms - FORM, Failure life, Failure Probability, MCS, Solder Joints

\section{INTRODUCTION}

The soldering is the most popular joining technology in the electronic industry. The successful estimation of lifetime of solder joint highly depends on the degree of accurate modeling of the stress and strain related to the strength of the solder joint. The main cause of failure in solder joints is considered to be thermo-mechanical stresses, caused by differences in the coefficient of thermal expansion (CTE) between the chip and the substrate. Also, the package variables including the die size, the package size, the ball count, the pitch, the mold compound and the substrate material affect the failure life of solder joints.[1] However, it is not easy to consider all of the variables. In this study, the material of solder joint, the materials of substrates, the height of solder, the Distance of the solder joint from the Neutral Point (DNP), the temperature variation and the dwell time were considered. Furthermore, experimental results obtained from thermal fatigue tests are compared to that from theoretical fatigue failure life equations. The effects of

Submitted date: April 28, 2007.

This work was supported by the Brain Korea 21 project in 2007..

O.S. Lee is with the School of Mechanical Engineering, InHa University, Incheon, Korea, 402-751 (e-mail: leeos@inha.ac.kr)..

Y.C. Park is with the Department of Mechanical Engineering, InHa University, Incheon, Korea, 402-751 (e-mail: yeonchang_park@yahoo.co.kr).

D.H. Kim is with Department of Mechanical Engineering, InHa University, Incheon, Korea, 402-751 (e-mail: kdonghyeok77@yahoo.co.kr). varying boundary conditions on the failure probability of the solder joint are also studied by using the probabilistic approach methods such as the First Order Reliability Method (FORM) and Monte Carlo Simulation (MCS).

\section{FAtigue FAILURE MODELS}

A generalized fatigue damage law for metals has been proposed on the basis of cumulative stored visco-plastic strain energy density. The cyclic shear fatigue life $\bar{N}_{f}$ is related to $\Delta W$ in a stabilized fatigue cycle by the equation[2]

$$
\bar{N}_{f}=\frac{1}{2}\left[\frac{\Delta W}{W_{f}^{\prime}}\right]^{\frac{1}{c}}
$$

$$
\text { Where } \begin{aligned}
c & =\text { fatigue ductility exponent } \\
\bar{N}_{f} & =\text { cycles-to-failure } \\
W_{f}^{\prime} & =\text { intercept energy term, a material constant } \\
\Delta W & =\text { visco-plastic strain energy density per cycle }
\end{aligned}
$$

The following well-known Manson-Coffin plastic strain-fatigue life relationship a special stress limited case of this generalized fatigue damage function.

$$
\bar{N}_{f}=\frac{1}{2}\left[\frac{\Delta \gamma}{2 \varepsilon_{f}^{\prime}}\right]^{\frac{1}{c}}
$$

Where $\Delta \gamma=$ cyclic shear strain range

$$
\varepsilon_{f}^{\prime}=\text { fatigue ductility coefficient }
$$

Where, $c$ and $2 \varepsilon_{f}^{\prime}$ are defined below, respectively.

$$
2 \varepsilon_{f}^{\prime} \approx 0.65
$$

$$
c=-0.442 \times-6 \times 10^{-4} T_{m}+1.74 \times 10^{-2} \ln \left(1+\frac{360}{t_{D}}\right)
$$


Where $T_{m}=$ mean cyclic solder joint temperature

$t_{D}=$ half-cycle dwell time (min)

The cyclic strain range is given by

$$
\Delta \gamma=F \cdot \frac{L_{D}}{h} \cdot \Delta \alpha \cdot \Delta T
$$

Where $F$ = empirical "nonideal" factor indicative of deviations of real solder joints from idealizing assumptions and accounting for secondary and frequently untractable effects $F \approx 1.27$ for column-like leadless solder attachments, $F \approx 1.0$ for solder attachments utilizing compliant leads

$L_{D}=$ Distance of the solder joint from the Neutral Point (DNP)

$h \quad=$ solder joint height, solder diameter

$\Delta \alpha=$ absolute difference in coefficients of thermal expansion of solder joint and substrate, $\triangle C T E$ $\Delta T=$ cyclic temperature swing

Thus, from combining (2), and (5), the cyclic life of surface mount solder attachment is obtained as [2]

$$
\bar{N}_{f}=\frac{1}{2}\left[F \cdot \frac{L_{D} \cdot \Delta \alpha \cdot \Delta T}{2 \varepsilon_{f}^{\prime} \cdot h}\right]^{\frac{1}{c}}
$$

\section{FAILURe Probability Models}

The failure probability is calculated using the FORM that is one of the methods utilizing reliability index. The FORM is denoted from the fact that it is based on a first-order Taylor series approximation of the Limit State Function (LSF) [3], which is defined as:

$$
Z=R-L
$$

Where $R$ is the resistance normal variable, and $L$ is the load normal variable. Assuming that $R$ and $L$ are statistically independent normal-distributed random variables, the variable will also be normal-distributed. The event of failure occurs, when $R<L$ (i.e. $Z<0$ ). The failure probability is given as below.

$$
\begin{aligned}
P F & =P[Z<0] \\
& =\int_{-\infty}^{0} \frac{1}{\sigma_{Z} \sqrt{2 \pi}} \exp \left\{-\frac{1}{2}\left(\frac{Z-\mu_{Z}}{\sigma_{Z}}\right)^{2}\right\} d Z=\Phi(-\beta)
\end{aligned}
$$

Where $\mu_{Z}$ and $\sigma_{Z}$ are the mean and standard deviation of the variable $Z$, respectively. And $\beta$ is the reliability index. Rackwitz and Fiessler proposed a method to estimate the reliability index using the procedure shown in Fig.1[4],[5]. The MCS technique is used to check the accuracy of the results out of the FORM.

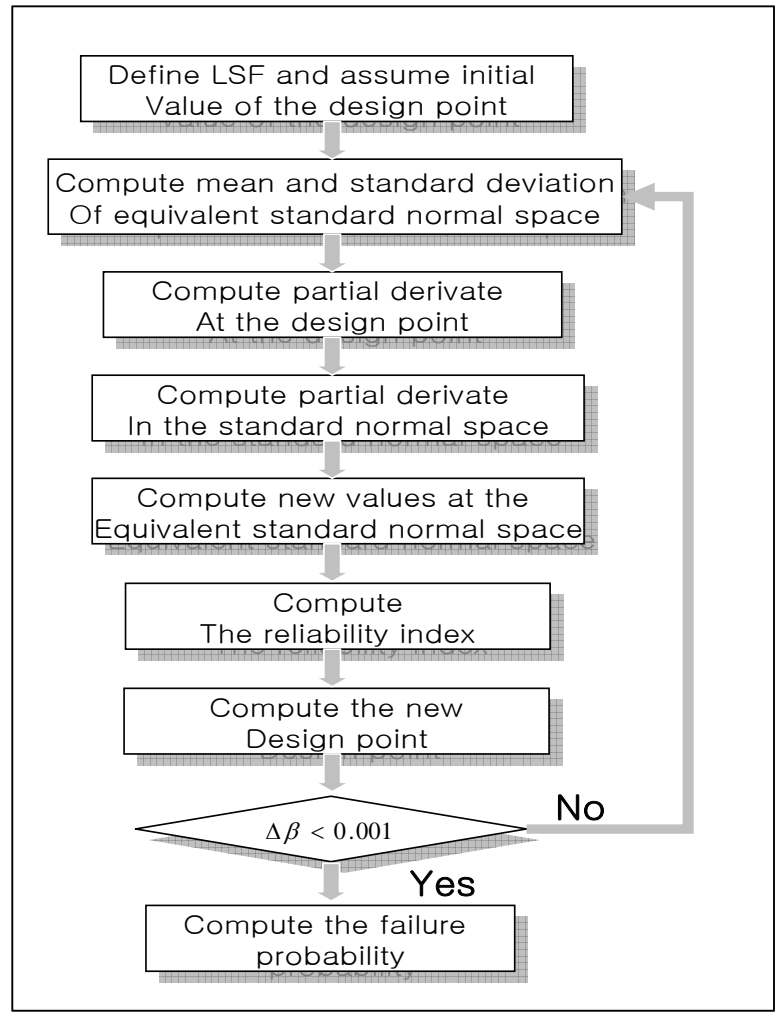

Fig. 1 Processing of computing the reliability index

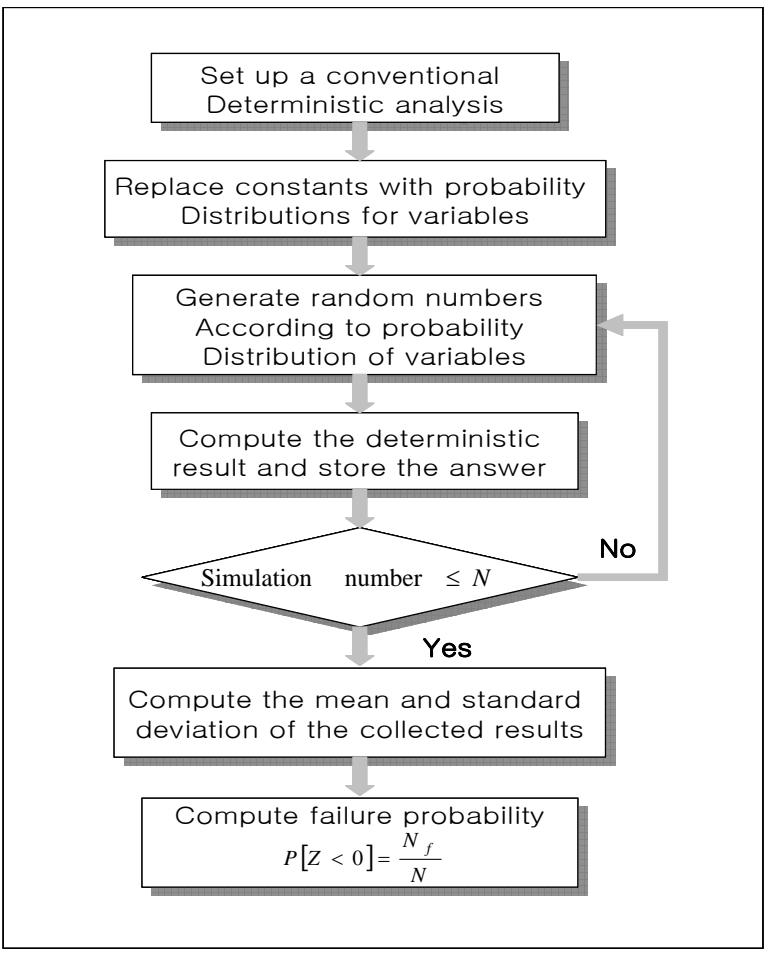

Fig.2 Processing of computing the failure probability using the MC 
Proceedings of the World Congress on Engineering 2007 Vol II

WCE 2007, July 2 - 4, 2007, London, U.K.

\begin{tabular}{|c|c|c|c|c|c|c|c|c|}
\hline & Sample 1 & Sample 2 & Sample 3 & Sample 4 & Sample 5 & Sample 6 & Sample 7 & Sample 8 \\
\hline \hline $\begin{array}{c}L_{D}(\mathrm{DNP}) \\
(\mathrm{m})\end{array}$ & 0.00735 & 0.00735 & 0.0176 & 0.0176 & 0.0106 & 0.0106 & 0.0092 & 0.0092 \\
\hline $\begin{array}{c}\text { Solder } \\
\text { Material }\end{array}$ & $\begin{array}{c}\text { Sn4Ag0.5C } \\
\mathrm{u}\end{array}$ & Sn4Ag0.5Cu & Sn4Ag0.5Cu & $63 \mathrm{SnPb}$ & $63 \mathrm{SnPb}$ & $63 \mathrm{SnPb}$ & $63 \mathrm{SnPb}$ & $63 \mathrm{SnPb}$ \\
\hline $\begin{array}{c}\text { Substrate } \\
\text { Material }\end{array}$ & $\mathrm{BT}$ & $\mathrm{BT}$ & FR4 & FR4 & FR4 & FR4 & FR4 & FR4 \\
\hline $\begin{array}{c}\Delta \alpha(\mathrm{ppm} / \\
\left.{ }^{\circ} \mathrm{C}\right)\end{array}$ & 7.5 & 7.5 & 4.5 & 7.6 & 7.6 & 7.6 & 7.6 & 7.6 \\
\hline$\Delta T\left({ }^{\circ} \mathrm{C}\right)$ & 180 & 100 & 165 & 165 & 165 & 165 & 165 & 165 \\
\hline$h(\mathrm{~m})$ & 0.00035 & 0.00035 & 0.00075 & 0.00075 & 0.000508 & 0.000508 & 0.000406 & 0.000508 \\
\hline${ }^{c}$ & -0.40699 & -0.41599 & -0.41149 & -0.41149 & -0.41149 & -0.40774 & -0.41149 & -0.41149 \\
\hline $\begin{array}{c}\text { Dwell } \\
\text { Time(min) }\end{array}$ & 15 & 15 & 15 & 15 & 15 & 12 & 15 & 15 \\
\hline $\begin{array}{c}\text { Failure life } \\
\text { of equation } \\
\text { (cycles) }\end{array}$ & 611 & 2154 & 1278 & 996 & 1228 & 1358 & 1005 & 1733 \\
\hline $\begin{array}{c}\text { Failure life } \\
\text { of test } \\
\text { cycles) }\end{array}$ & 620 & 1170 & 1436 & 722 & 1305 & 1320 & 1500 & 1100 \\
\hline
\end{tabular}

Table1. Random variables and parameters used in the case study

Most engineering MCSs are usually performed by using the steps shown in Fig. 2 [4].

\section{The STANDARD OF FAILURE Estimation}

The failure probability of the solder joint is affected by varying boundary conditions and the LSF including varying boundary conditions may be defined to estimate the influence of boundary conditions to the failure probability accordingly. In this paper, the modified Manson-Coffin plastic strain-fatigue life relationship is used to formulate the LSF given as below.

$Z=\bar{N}_{f}-N_{S}=\frac{1}{2}\left[F \cdot \frac{L_{D} \cdot \Delta \alpha \cdot \Delta T}{2 \varepsilon_{f}^{\prime} \cdot h}\right]^{\frac{1}{c}}-N_{S}$

Where $N_{s}=$ specified fatigue cycles

\section{CASE STUDY}

For estimating about reliability of solder joints, results of thermal fatigue test of eight samples are utilized in this study. Each sample has difference variables. The random variables in Table 1 have been utilized to estimate the failure probability of the solder joint. The standard of failure in this study is defined as the first failure life cycle.[1],[6],[7],[8]

\begin{tabular}{|c|c|c|c|c|c|c|}
\hline & $\mathrm{F}$ & $L_{D}$ & $\Delta \alpha$ & $\Delta T$ & $h$ & $c$ \\
\hline $\begin{array}{c}\text { C.O. } \\
\mathrm{V}\end{array}$ & 0.001 & 0.004 & 0.005 & 0.01 & 0.004 & 0.001 \\
\hline
\end{tabular}

Table 2. C.O.V of varying boundary conditions

The C.O.Vs of varying boundary condition listed in Table 2 are taken from some reference. [9] The C.O.V is defined as below with the standard deviation, $\sigma_{Z}$ and the mean, $\mu_{Z}$

$$
\text { C.O.V }=\frac{\sigma_{Z}}{\mu_{Z}}
$$

\section{RESULTS AND DISCUSSIONS}

Fig. 3 shows the relationship between the failure probability of the solder joint and the cyclic temperature swing. It is confirmed that the failure probability increases with increase of the cyclic temperature swing.

Fig. 4 shows that the relationship between the failure probability and the difference in CTE for solder material. It is found that the failure probability increases with increase of the difference in CTE. The reliability of lead-free solder joint (Sn4Ag0.5Cu) is estimated better than that of lead solder joint 
Proceedings of the World Congress on Engineering 2007 Vol II WCE 2007, July 2 - 4, 2007, London, U.K.

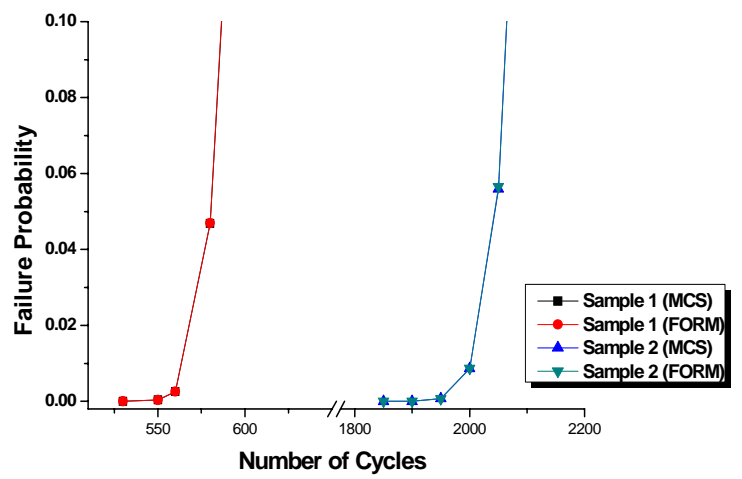

Fig.3 the relationship between the failure probability of the solder joint and cyclic temperature swing

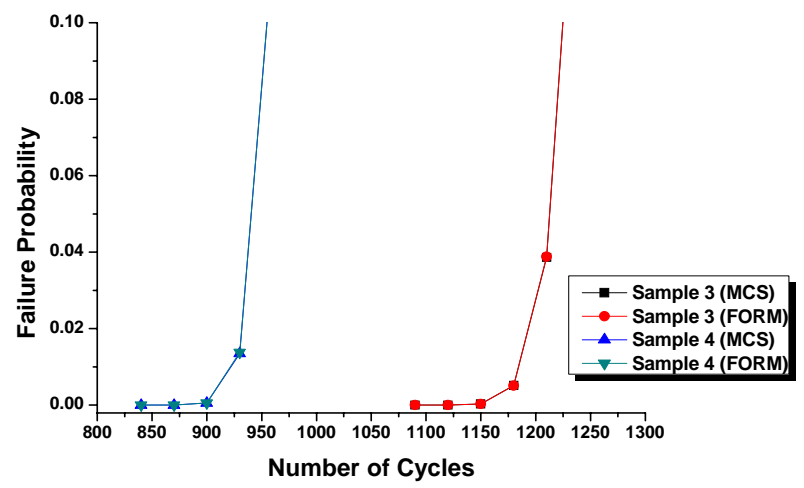

Fig.4 Relationship between the failure probability and solder material (difference in CTE)

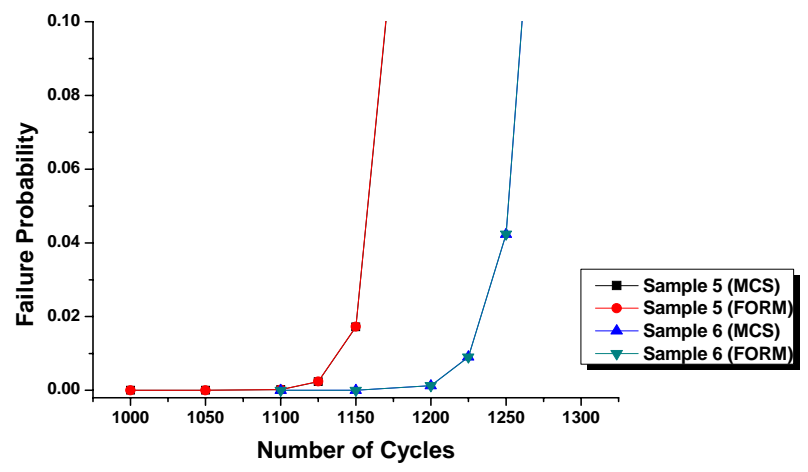

Fig.5 Relationship between the failure probability and dwell time

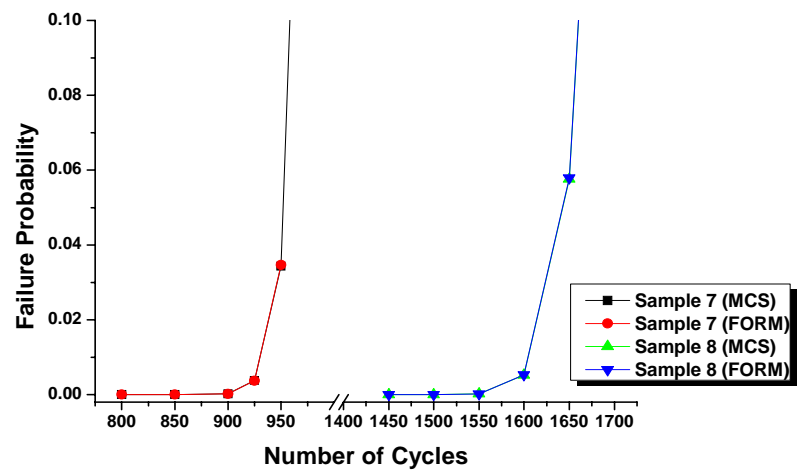

Fig. 6 Relationship between the failure probability and solder joint height

\begin{tabular}{|c|c|c|c|c|}
\hline & $\begin{array}{c}\text { Failure } \\
\text { life(cycles) }\end{array}$ & MCS & FORM & $\begin{array}{c}\text { Differenc } \\
\text { e rate } \\
{[\%]}\end{array}$ \\
\hline \hline Sample 1 & 580 & 0.04691 & 0.04693 & 0.0426 \\
\hline Sample 2 & 2050 & 0.05594 & 0.05656 & 1.0962 \\
\hline Sample 3 & 1210 & 0.03866 & 0.03884 & 0.4634 \\
\hline Sample 4 & 930 & 0.01351 & 0.01383 & 2.3138 \\
\hline Sample 5 & 1150 & 0.01722 & 0.01726 & 0.2317 \\
\hline Sample 6 & 1250 & 0.04232 & 0.4246 & 0.3297 \\
\hline Sample 7 & 950 & 0.03433 & 0.3465 & 0.9235 \\
\hline Sample 8 & 1650 & 0.05764 & 0.0579 & 0.4491 \\
\hline
\end{tabular}

Table 3. Difference ratio of the failure probabilities obtained by using the FORM and the MCS. ; difference ratio=100 $\times($ FORM-MCS $) /$ FORM

(63SnPb).

Fig. 5 shows that the relationship between the failure probability and the dwell time. It is found that the failure probability increases with increase of the dwell time.

Fig. 6 shows the relationship between the failure probability and the solder joint height. For this case, it is noted that the relationship obtained by using the failure life of equation and the one estimated from experimental failure life test do not agree each other. Sample 7 and sample 8 have same variables except the die size and the solder ball diameter.[1] We speculate the mismatch in Fig. 6 the exclusion of the die size in the fatigue life equation.

Table 3 shows the difference ratio of the failure probabilities obtained by using the FORM and the MCS. It is recognized that the results by the FORM and the MCS are almost the same. The difference ratios are found to be less than $2.3 \%$.

\section{CONCLUSION}

In this paper, reliability of solder joints under varying conditions is estimated by the FORM and MCS. The FORM is utilized to extract useful technical information in carrying out the effective failure control. The results obtained by the FORM are verified by comparing to those from the MCS. The following results are obtained:

1) The failure probability increases with increases in number of thermal fatigue cycles.

2) The failure probability decreases with decrease in the cyclic temperature swing, the difference in CTE and dwell time.

3) It is found that the result from the theoretical fatigue failure life equation has similar trend with one from experimental test except the case for the different height of solder joint.

4) The FORM is found to be efficient techniques to estimate the failure probability of the solder joint under 
Proceedings of the World Congress on Engineering 2007 Vol II

WCE 2007, July 2 - 4, 2007, London, U.K.

temperature boundary conditions. It is verified by comparing the results out of the MCS.

\section{REFERENCES}

[1] R. Darveaux, J. Heckman, A. Syed, A. Mawer, "Solder joint fatigue life of fine pitch BGAs- impact of design and material choices", Microelectronics Reliability 40, 2000, pp. 1117-1127

[2] J.H.Lau, Solder Joint Reliability Theory and Application, Van Nostrand Reinhold, 1991, pp. 556-563.

[3] A. Haldar, S. Mahadevan, Probability, Reliability, and Statistical Methods in Engineering Design, John Wiley \& Sons, Inc, 2000, pp. ch7

[4] O.S. Lee, S.S. Choi and D.H. Kim, "Effect of Varying Boundary Conditions on the Buried Pipelines", Solid State Phenomena, Vol. 110, 2006, pp. 221 230.

[5] O.S. Lee, D.H. Kim "Reliability of Buried Pipeline Using FORM and Monte Carlo Simulation”, Key Engineering Materials, Vol. 321-323, 2006, pp. 1543-1547.

[6] A. Guedon-Gracia, E. Woirgard, C. Zardini, "Correlation between Experimental Results and FE Simulations to Evaluate Lead-Free BGA Assembly Reliability”, Microelectronics Reliability 45, 2005, pp. 1652-1657

[7] http://www.amkor.co.kr/

[8] J.E. Ryu, T.K. Hwang, and S.B. Lee, "The influence of microstructure development on the thermal fatigue behaviors of BGA solder joint", unpublished

[9] O.S. Lee, M.J. Hur, J.S. Hawong, N.H. Myoung, and D.H. Kim, "Reliability Estimation of Solder Joint by Using the Failure Probability", Key Engineering Materials, Vol. 326-328, 2006, pp. 621-624 